\title{
Toxicity of Sodium Molybdate and Sodium Dichromate to Daphnia magna Straus Evaluated in Acute, Chronic, and Acetylcholinesterase Inhibition Tests
}

\author{
Teresa C. Diamantino, ${ }^{*} \uparrow, 1$ Lucia Guilhermino, $\ddagger$ Elisabete Almeida, $\dagger$ and Amadeu M. V. M. Soares* \\ * Instituto do Ambiente e Vida, Departamento de Zoologia, Largo Marquês de Pombal, Universidade de Coimbra, 3000 Coimbra, Portugal; \\ $\dagger$ Instituto Nacional de Engenharia e Tecnologia Industrial, Estrada do Paço do Lumiar, 1699 Lisboa Codex, Portugal; and \\ \$Instituto de Ciências Bimédicas de Abel Salazar, Departamento de Estudos de Populações, Laboratório de Ecotoxicologia/Centro de Investigação Marinha \\ e Ambiental, Universidade do Porto, Lg Prof. Abel Salazar, 2, 4050 Porto, Portugal
}

Received March 18, 1999

As a result of a widespread application in numerous industrial processes, chromium is a contaminant of many environmental systems. Chromium and their compounds are toxic to both invertebrates and vertebrates and, for this reason, there has been a search for suitable and less toxic alternatives. Molybdenum compounds have been studied as alternative to chromium compounds for some industrial applications. The toxicity of chromium is well known but the effects of molybdenum and molybdenum mining on natural populations and communities of freshwater invertebrates have not often been studied. However, chromium, and molybdenum (and their compounds) are included in the same list (List II) of European Union dangerous substances. In this study, the acute and chronic effects of sodium molybdate and sodium dichromate to Daphnia magna Straus were evaluated. Furthermore, in vitro and in vivo effects of these two metals on acetylcholinesterase (AChE) activity of $D$. magna Straus were investigated. $\mathrm{LC}_{50}$ values determined at $48 \mathrm{~h}$ were 0.29 and $2847.5 \mathrm{mg} \mathrm{L}^{-1}$ for chromium (as sodium dichromate) and molybdenum (as sodium molybdate), respectively. No significant in vitro effects of both metals on $\mathrm{AChE}$ were found. However, both toxicants inhibited $\mathrm{AChE}$ in vivo at concentrations under the respective 48-h $\mathrm{LC}_{50}$ values. Both sodium dichromate and sodium molybdate inhibited the reproduction and growth of D. magna, but the concentrations inducing significant effects were different for the two chemicals. Sodium molybdate had significant lower toxicity to $D$. magna Straus than sodium dichromate. (1) 2000 Academic Press

Key Words: sodium molybdate; sodium dichromate; acute and chronic effects; AChE, Daphnia magna.

\section{INTRODUCTION}

Heavy metals are widely recognized as highly toxic and dangerous to organisms (Mance, 1987). As a result of wide-

\footnotetext{
${ }^{1}$ To whom correspondence should be addressed at IMP/LTR, Instituto Nacional de Engenharia e Tecnologia Industrial, Estrada do Paço do Lumiar, 1699 Lisboa Codex, Portugal. Fax: +351-21-7160901. E-mail: teresa.diamantino@mail.ineti.pt.
}

spread application in numerous industrial processes, chromium is a contaminant of many environmental systems (Cohen et al., 1993). Industrial uses of chromium include metal finishing industry, production of paints and pigments, tanning, wood preservation, chromium chemicals production, pulp and paper production, and metal smelting (Pawlisz et al., 1997). One of the major uses of environmentally hazardous chemicals is in the metal finishing industry. Sodium dichromate is the most important of the industrial chromium chemicals; it is used as the starting compound for almost all chromium compounds (Anger et al., 1986) and is firmly established in the metal finishing field (Biestek and Weber, 1976). One of the environmental problems of these industries is the elimination of hexavalent chromium compounds, which are used extensively for the passivation of zinc, and for zinc-based coatings and surfaces. The elimination of these toxic chemicals from metal processing, particularly in the automobile industry where chromates are widely used for the protection of zinc-plated parts, is considered a priority within the European Union (SI, 1997).

Molybdenum compounds are used in catalysis, luberfization, flame retardancy and smoke suppression, pigments, agriculture, and corrosion inhibition (Sebenik et al., 1990). At high concentrations, molybdenum is toxic to many organisms, including mammals and freshwater invertebrates (Khangarot, 1991). The effects of molybdenum or molybdenum mining on natural populations or communities of freshwater invertebrates have not often been studied (Whiting et al., 1994). Based on toxicological studies from the literature, some authors have been studying alternatives to chromium hexavalent compounds for passivation of zinc coatings based on molybdenum compounds (Tang et al, 1994; Wharton et al., 1996; Almeida et al., 1998). Despite the differences of toxicity between chromium and molybdenum reported in the literature, both metals (and their compounds) are included in the List II of European dangerous substances directive (CEC, 1976). 
Daphnia magna is widely used as a test organism in aquatic toxicology (Adema, 1978; Meer et al., 1988; Soares et al., 1992). Bioassays involving this species are required for the assessment of the potential impact of new chemicals on the aquatic environment (Soares et al., 1991). Acute and chronic bioassays with this species are the most widely used test methods for the toxicity assessment of chemical compounds and effluents. In acute tests the measured parameter is death, while in chronic tests the inhibition of normal reproduction and growth are the most used endpoints for toxicity evaluation. However, chronic tests are particularly time-consuming and expensive. For this reason, in recent decades there have been efforts to develop and validate alternative methods to conventional toxicity tests (Blaise et al., 1997; Tylor et al., 1998).

Enzymes are known to play a crucial role in vital functions of all organisms. The inhibition of cholinesterases has been widely used as a specific biomarker for organophosphate and carbamate pesticides, being considered a "gold standard biomarker" (Peakall, 1994). However, studies published in recent years indicate that some metals (including chromium) might also inhibit these enzymes, under both in vivo and/or in vitro conditions (Labrot et al., 1996; Payne et al., 1996; Guilhermino et al., 1998).

In this study, the toxicity of sodium dichromate and sodium molybdate to D. magna was evaluated using conventional 48-h acute tests, in vivo and in vitro acetylcholinesterase (AChE) inhibition assays, and 21-day chronic tests. Furthermore, the effect of the color of sodium dichromate in the results of an in vitro AChE inhibition test was also investigated.

\section{MATERIALS AND METHODS}

In the following sections total chromium and molybdenum concentrations refer to the concentrations of the metallic element in the medium.

Parent animals were cultured in ASTM hard water (ASTM, 1980) with an organic additive (Baird et al., 1989), in groups of 10 animals per $1000 \mathrm{ml}$ of medium, and fed with the algae Chlorella vulgaris ( $0.322 \mathrm{mg}$ carbon/daphnia/day). The photoperiod was $16 \mathrm{~h}$ light: $8 \mathrm{~h}$ dark and the temperature was $20 \pm 1{ }^{\circ} \mathrm{C}$.

\subsection{Acute and Chronic Tests}

Tests were carried out in ASTM hard water (ASTM, 1980), with animals from a single clone (clone A, sensu; Baird et al., 1989) and initiated with third- to fifth-brood neonates $(<24 \mathrm{~h})$. In acute tests, organisms were not fed during the experiments and no organic additive was used. For conventional acute tests, 20 animals were used per treatment, in groups of 5 per $100 \mathrm{ml}$ of test solution. Each test was carried out for $48 \mathrm{~h}$. The criterion of toxic effect was death, recognized by immobilization after stimulation by a bright light. In chronic tests, the organisms were cultured in ASTM medium with an organic additive (Baird et al., 1989), one animal per $1000 \mathrm{ml}$ of medium, and fed with the algae $C$. vulgaris $(0.322 \mathrm{mg}$ carbon/daphnia/day). Each test was carried out for 21 days. Animals were transferred to newly prepared test solutions three times a week (i.e., every other day). One control and six toxicant concentrations with 10 replicates for each treatment were used. Endpoints were reproduction, growth, and mortality. In both acute and chronic tests, temperature and photoperiod were as described above.

\subsection{In Vitro AChE Inhibition Test}

Tests were performed as described in Guilhermino et al. (1996) with the following modifications: animals were cultured for $48 \mathrm{~h}$ in the presence of food; homogenates were stored at $-20^{\circ} \mathrm{C}$ for a maximum of 1 week. The incubation procedure was performed according to Herbert et al. (1995/1996). In each experiment, homogenate samples $(495 \mu \mathrm{l})$ were incubated at $20^{\circ} \mathrm{C}$ with $5 \mu \mathrm{l}$ of each test solution, for $30 \mathrm{~min}$. For each compound, a water control and five concentrations of the metallic element were used (12.5, $25,50,75$, and $100 \mathrm{mg} \mathrm{L}^{-1}$ ). Three replicates per treatment were used. The activity of AChE was determined, in triplicate, by the Ellman method (Ellman et al., 1961) adapted to microplate (Herbert et al., 1995/1996). The protein content of the samples was determined according to the Bradford technique (Bradford, 1976) with the modifications described by Herbert et al. (1995/1996). The activity of AChE in each sample was presented as the mean of the three determinations performed and expressed in units $(\mathrm{U})$ per milligram of protein $(1 \mathrm{U}=1 \mathrm{nmol}$ of substrate hydrolyzed per minute). A Labsystems Multiskan MS microplate reader was used.

Sodium dichromate solutions presented an orange color interfering with both $\mathrm{AChE}$ and protein determinations. For this reason, a correction test for color interference as described above but without Daphnia homogenate was performed in parallel. The objective of this procedure is to account for eventual effects due to the color of the chromium solutions.

\subsection{In Vivo AChE Inhibition Tests}

Tests were carried out according to Guilhermino et al. (1996) with the following modifications: 60 animals were used per treatment, in groups of 20 per $1000 \mathrm{ml}$ of test solution. Neonates were cultured for $48 \mathrm{~h}$. Preparation of homogenates and the determinations of AChE activity and protein content were performed as described above for the in vitro $\mathrm{AChE}$ inhibition tests. 
TABLE 1

Range of Concentrations of Molybdenum and Chromium Tested in Conventional Acute, Chronic, in Vivo, and in Vitro AChE Inhibition Tests

\begin{tabular}{lcc}
\hline & $\begin{array}{c}\text { Chromium } \\
\left(\mathrm{mg} \mathrm{L}^{-1}\right)\end{array}$ & $\begin{array}{c}\text { Molybdenum } \\
\left(\mathrm{mg} \mathrm{L}^{-1}\right)\end{array}$ \\
\hline Conventional acute tests & $0.075-0.6$ & $1500-48,000$ \\
In vivo AChE Inhibition tests & $0.025-0.3$ & $250-3000$ \\
In vitro AChE Inhibition tests & $12.5-100$ & $12.5-100$ \\
21-day chronic tests & $0.0125-0.125$ & $50-250$ \\
\hline
\end{tabular}

Note. Values are total concentrations of each metallic element.

\subsection{Chemicals and Test Solutions}

Acetylthiocholine, acid dithiobisnitrobenzoate, and $\gamma$-bovine globulins were purchased from Sigma. Bradford reagent was from Bio-Rad, and all the other chemicals were from Merck. For all the tests, stock solutions were prepared in nanopure water (conductivity $<5 \mu \mathrm{S} / \mathrm{cm}$ ). The range of concentrations tested for each chemical is summarized in Table 1.

\subsection{Data Analysis}

$\mathrm{LC}_{50}$ values for conventional acute tests and $\mathrm{EC}_{50}$ values for in vivo $\mathrm{AChE}$ inhibition assays were determined by probit analysis (Finney, 1971). Data from chronic tests (growth and reproduction) were analyzed with one-way ANOVA. NOEC and LOEC were determined by Dunnett's test (Zar, 1996). Only the organisms for which death occurred after delivery of the first brood and before the end of the tests were considered for statistical analysis. $\mathrm{EC}_{50}$ values for reproduction and growth were also calculated using probit analysis (Finney, 1971). NOEC and LOEC values for mortality were determined using Fisher's Exact test (EPA, 1989) and 21-day $\mathrm{LC}_{50}$ values were calculated by probit analysis (Finney, 1971). Data from AChE inhibition tests were analyzed using a hierarchical (nested) analysis of variance. NOEC and LOEC were determined by Dunnett's test (Zar, 1996). The significance level was 0.05 .
TABLE 2

48-h LC $_{50}$ Values of Metallic Elements (Chromium and Molybdenum) for Daphnia magna and Their Corresponding 95\% Confidence Limits

\begin{tabular}{lcc}
\hline Chemical $\left(\mathrm{mg} \mathrm{L}^{-1}\right)$ & $48-\mathrm{h} \mathrm{LC}_{50}$ & $95 \% \mathrm{CL}$ \\
\hline Chromium & 0.29 & $0.269-0.315$ \\
Molybdenum & 2847.5 & $2838.7-2857.0$ \\
\hline
\end{tabular}

\section{RESULTS}

In both acute and chronic tests, oxygen levels were always above $7.0 \mathrm{mg} \mathrm{L}^{-1}$ and $\mathrm{pH}$ variation was always lower than $1 \mathrm{U}$.

\subsection{Acute Tests}

The 48-h $\mathrm{LC}_{50}$ values determined for each metal element with the correspondent $95 \%$ confidence limits are presented in Table 2.

\subsection{Chronic Tests}

Each test organism was checked for body length at birth and at the end of the test, as well as for the total number of offspring (total reproduction). Significant effects in total growth and reproduction were found between the different chromium concentrations and the control (total growth: $F=74.48 ; d f=6,63 ; P<0.05$ ) (reproduction: $F=174.68$; $d f=6,63 ; P<0.05)$. For both reproduction and growth, LOEC was $0.0125 \mathrm{mg} \mathrm{L}^{-1}$ and NOEC was $0.025 \mathrm{mg} \mathrm{L}^{-1}$ (Table 3). For mortality, LOEC was $0.01 \mathrm{mg} \mathrm{L}^{-1}$ and NOEC $0.075 \mathrm{mg} \mathrm{L}^{-1}$ (Fisher Exact test: $A=10 ; B=10$; $a=10 ; b=6 ; P=0.043)$.

Relative to total growth, significant effects were also observed between all the molybdenum concentrations and the control (total growth: $F=35.52 ; d f=5,52 ; P<0.05$ ) (reproduction: $F=26.6$; $d f=5,54 ; P<0.05$ ). For reproduction and growth, the LOEC was $50 \mathrm{mg} \mathrm{L}^{-1}$ and NOEC was

TABLE 3

Sublethal (Total Growth and Reproduction) and Lethal Toxicity Endpoints Determined in Chronic Tests for Chromium and Molybdenum (Total Concentrations of Metallic Elements)

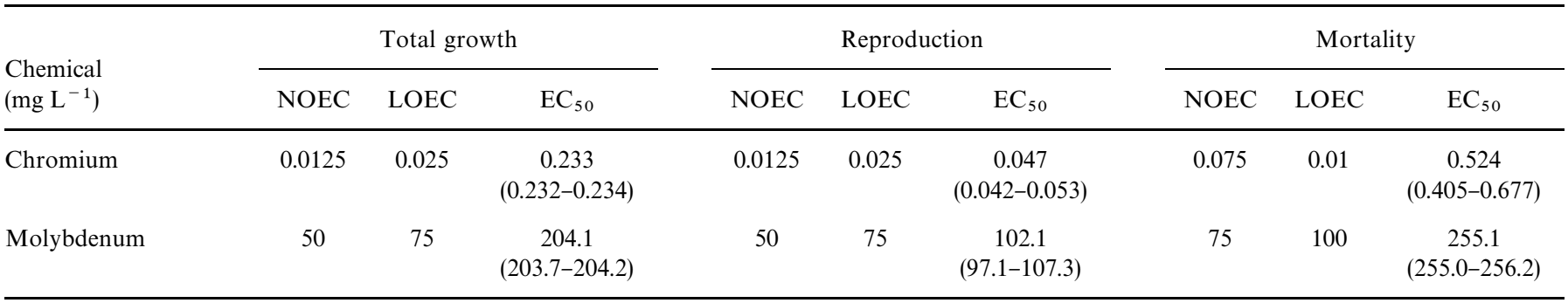

Note. $95 \%$ confidence limits are in parentheses. 


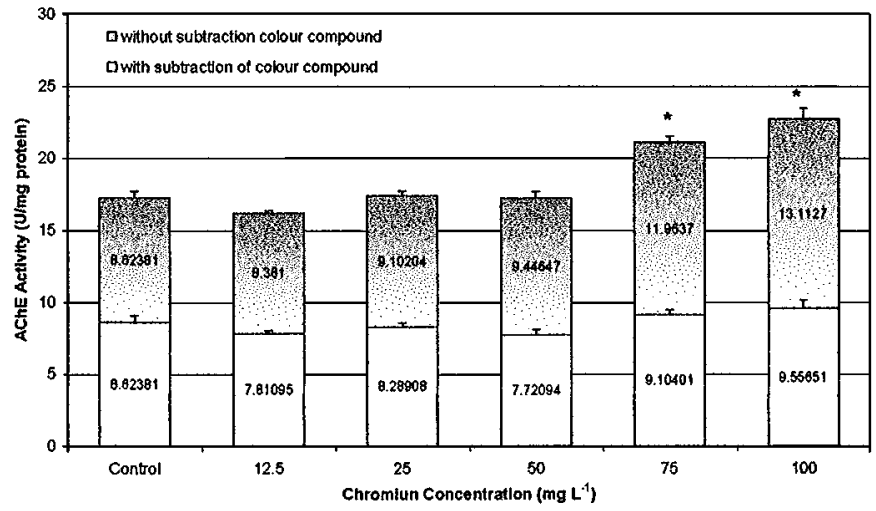

FIG. 1. Columns with points indicate the results of AChE activity without subtraction of the effect due to the color of chromium solution. White columns presents the in vitro effect of chromium on AChE activity with the subtraction of the effect of the compound color. Data are expressed as the mean of three samples (three measurements per sample) \pm SEM. (* significantly different at $P \leq 0.05$ ).

$75 \mathrm{mg} \mathrm{L}^{-1}$ (Table 3). Significant differences were also found in mortality (Fisher Exact test: $A=10 ; B=10 ; a=10$; $b=6 ; \quad P=0.043 ; \quad$ LOEC $=100 \mathrm{mg} \mathrm{L}^{-1}, \quad$ NOEC $=$ $75 \mathrm{mg} \mathrm{L}^{-1}$.

\subsection{In Vitro AChE Inhibition Tests}

The results obtained in the in vitro AChE tests suggest that chromium significantly increases the activity of the enzyme $(F=16.15 ; d f=5,12 ; P<0.05)$. However, the color of chromium solutions indicated interferences with the determination of both AChE activity and protein content (Fig. 1). After removal of the color effect, results indicate that chromium did not induce significant alterations in AChE activity. No significant effects of molybdenum on AChE were found ( $F=3.89 ; d f=5,12 ; P>0.05)$ (Fig. 2).

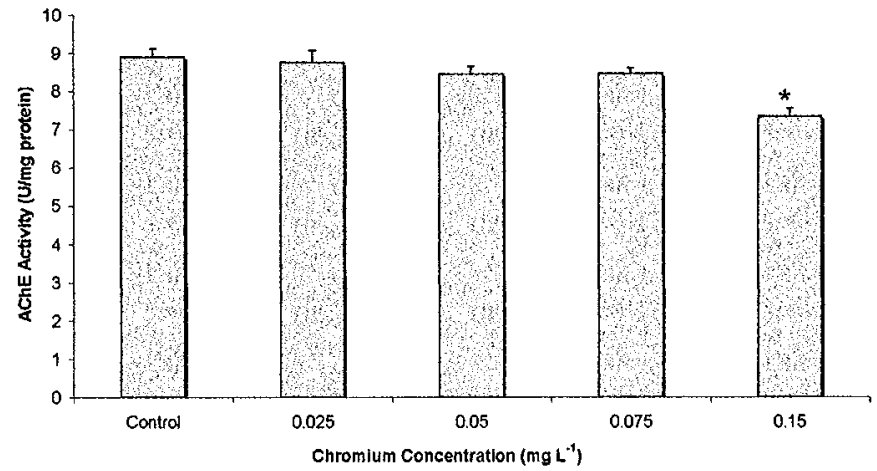

FIG. 3. In vivo effects of chromium on AChE activity. Data are expressed as the mean of three samples (three measurements per sample) \pm SEM. (* significantly different at $P \leq 0.05)$.

\subsection{In Vivo AChE Inhibition Tests}

Chromium significantly inhibited $\mathrm{AChE}$ activity in vivo (Fig. 3$)(F=10.97 ; d f=4,10 ; P<0.05)$ with a LOEC value of $0.15 \mathrm{mg} \mathrm{L}^{-1}$ and a NOEC value of $0.075 \mathrm{mg} \mathrm{L}^{-1}$. Molybdenum, in in vivo conditions, significantly inhibited $\mathrm{AChE}$ activity (Fig. 4$)(F=12.76 ; d f=4,10 ; P<0.05)$. The NOEC was $750 \mathrm{mg} \mathrm{L}^{-1}$ and the LOEC, $1500 \mathrm{mg} \mathrm{L}^{-1}$.

$\mathrm{EC}_{50}$ values for metallic elements determined by the in vivo AChE inhibition tests are provided in Table 4.

\section{DISCUSSION}

Considerable differences were found between the toxicities of chromium and molybdenum compounds to D. magna. Sodium molybdate revealed a lower toxicity for D. magna in all tests performed. The results of acute tests for chromium element obtained in this work are similar to corresponding $48-\mathrm{h} \mathrm{LC}_{50}$ reported in the literature by other

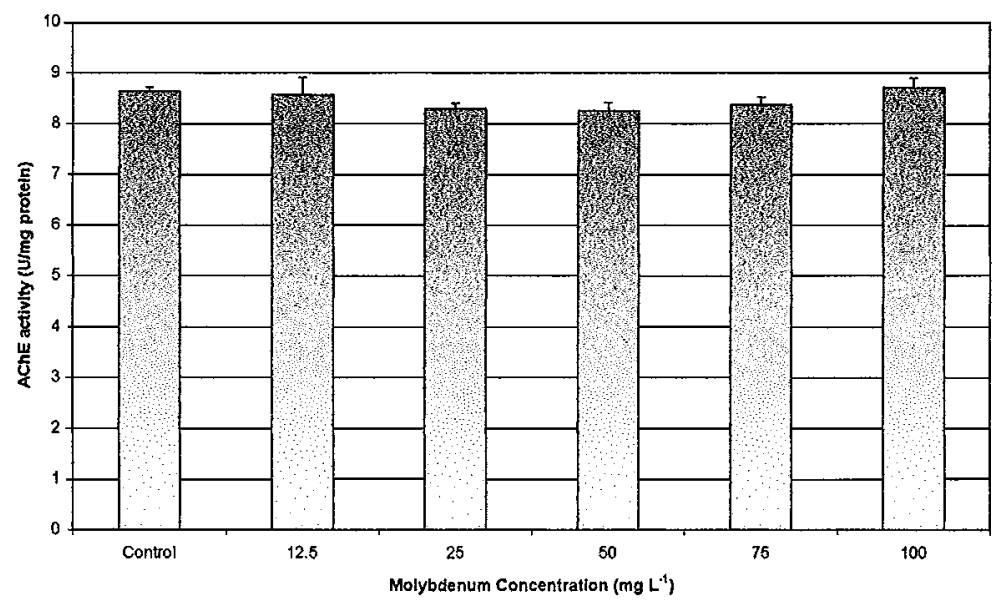

FIG. 2. In vitro effects of molybdenum on $\mathrm{AChE}$ activity. Data are expressed as the mean of three samples (three measurements per sample) $\pm \mathrm{SEM}$. 


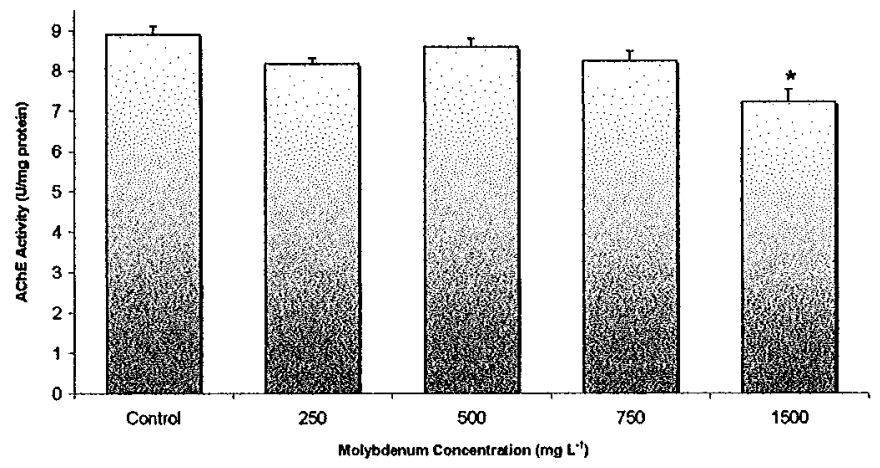

FIG. 4. In vivo effects of molybdenum on in vivo AChE activity. Data are expressed as the mean of three samples (three measurements per sample) \pm SEM. (* significantly different at $P \leq 0.05)$.

authors (0.42 $\left.\mathrm{mg} \mathrm{L}^{-1}\right)$ (0.229 $\left.\mathrm{mg} \mathrm{L}^{-1}\right)$ (Baird et al., 1991; Guilhermino et al., 1997). Molybdenum $\mathrm{LC}_{50}$ values determined in this study are comparable to $96-\mathrm{h}^{\mathrm{LC}_{50}}$ for sodium molybdate dihydrate as reported by Sebenik et al. (1990) (3940 $\mathrm{mg} \mathrm{L}^{-1}$ ) and 48-h $\mathrm{LC}_{50}$ for "molybdate" as reported by Kálmán (1994) (3220 $\left.\mathrm{mg} \mathrm{L}^{-1}\right)$.

The results obtained from chronic tests revealed that both sodium dichromate and sodium molybdate significantly inhibited reproduction and growth of D. magna (Figs. 5 and 6). The effects of reproduction observed in chronic tests with chromium are in good agreement with some authors (Anger et al., 1986). According to them, potassium dichromate concentrations higher than $0.1 \mathrm{mg} \mathrm{L}^{-1}$ significantly decrease offspring production and swimming ability of D. magna $\left(\mathrm{EC}_{50} 0.9 \mathrm{mg} \mathrm{L}^{-1}\right)$. Regarding the chronic tests with sodium molybdate, no comparable data could be found in the literature.

Inhibition of cholinesterases has been widely used as a biomarker for organophosphate and carbamate insecti-

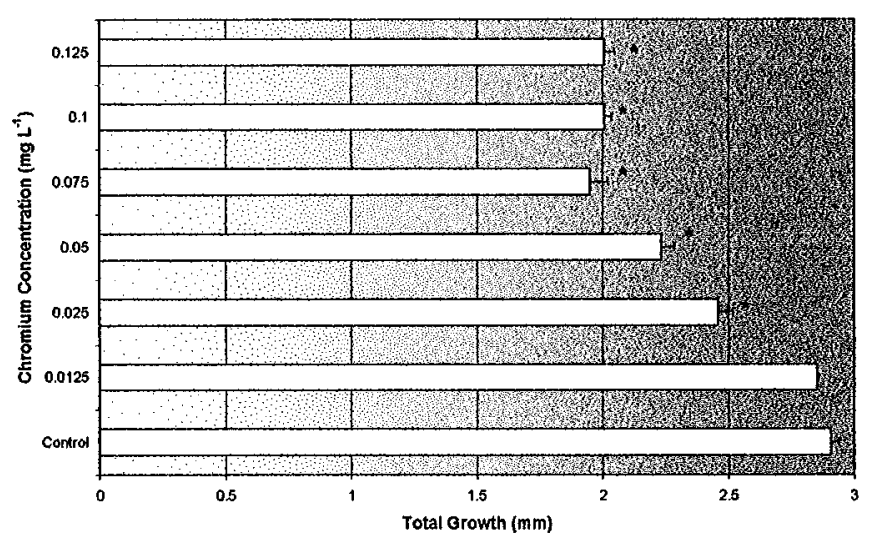

(a)
TABLE 4

NOEC, LOEC, and $\mathrm{EC}_{50}$ Values $\left(\mathrm{mg} \mathrm{L}^{-1}\right)$ (Concentrations of Metallic Elements) Determined from in Vivo AChE Inhibition Tests

\begin{tabular}{lccc}
\hline Chemical & NOEC & LOEC & EC $_{50}$ \\
\hline Chromium & 0.075 & 0.15 & 0.632 \\
& & & $(0.617-0.647)$ \\
Molybdenum & 750 & 1500 & $\begin{array}{c}26,492 \\
(22,258-31,531)\end{array}$ \\
\hline
\end{tabular}

Note. $95 \%$ confidence limits are in parentheses.

cides. The results obtained here agree with recent studies indicating that some metals (including chromium) may inhibit cholinesterases under both in vivo and in vitro conditions (Labrot et al., 1996; Payne et al. 1996; Guilhermino et al., 1998). At the concentrations tested in this study, chromium and molybdenum compounds did not inhibit AChE in vitro. However, a significant $\mathrm{AChE}$ inhibition in vivo was observed at concentrations under the corresponding $\mathrm{LC}_{50}$ values. These results suggest that the compounds are biotransformed in effective inhibitors inside the organism. Furthermore, these results also indicate that the in vivo $\mathrm{AChE}$ inhibition test is very sensitive, indicating significant effects at concentrations lower than those inducing death. The high sensitivity of the in vivo AChE test toward organophosphates reported by Guilhermino et al. (1996) was expected, considering the mechanism of action of these compounds. However, the high sensitivity of the in vivo AChE test relative to metals found in this study is quite surprising and supports the point of view that this test is advantageous for current ecotoxicity testing relative to conventional acute tests based on mortality.

The results obtained in AChE in vitro tests indicate that some precautions should be taken regarding the use of

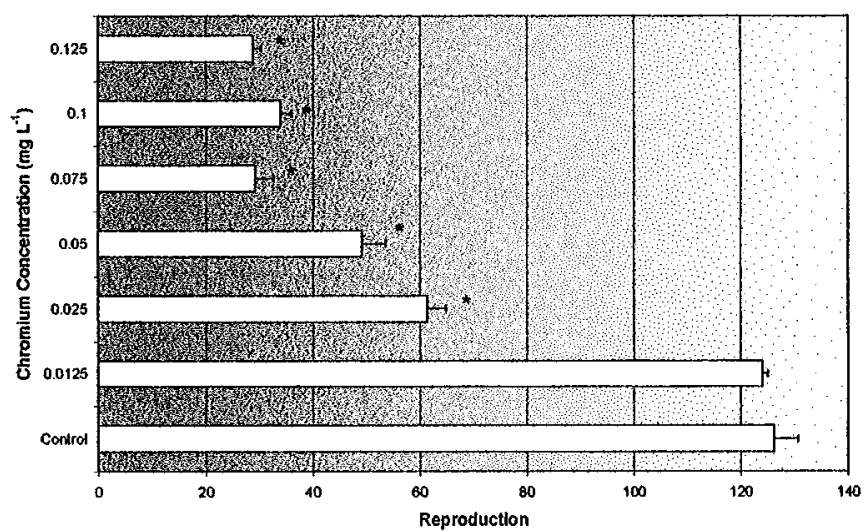

(b)

FIG. 5. Total growth (a) and total reproduction (b) for each concentration of chromium and for the control. Data are expressed as the mean \pm SEM (* significantly different at $P \leq 0.05$ ). 


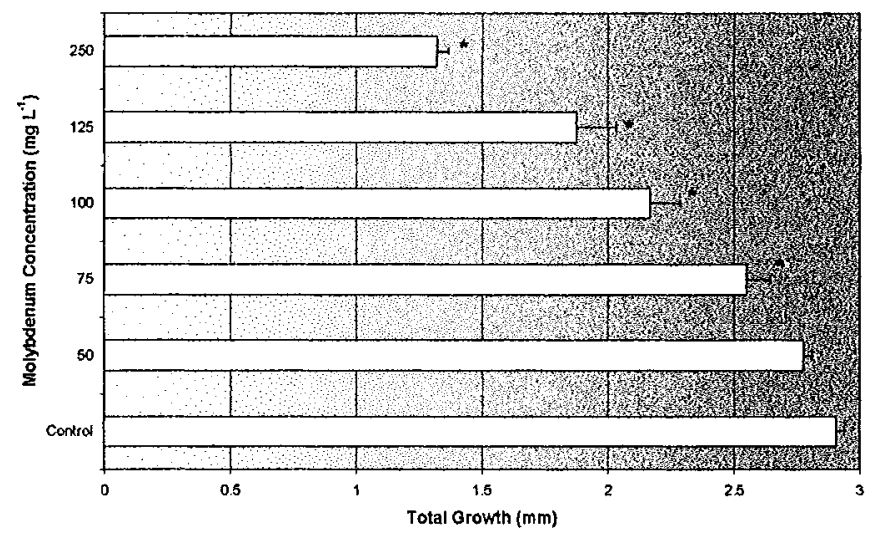

(a)

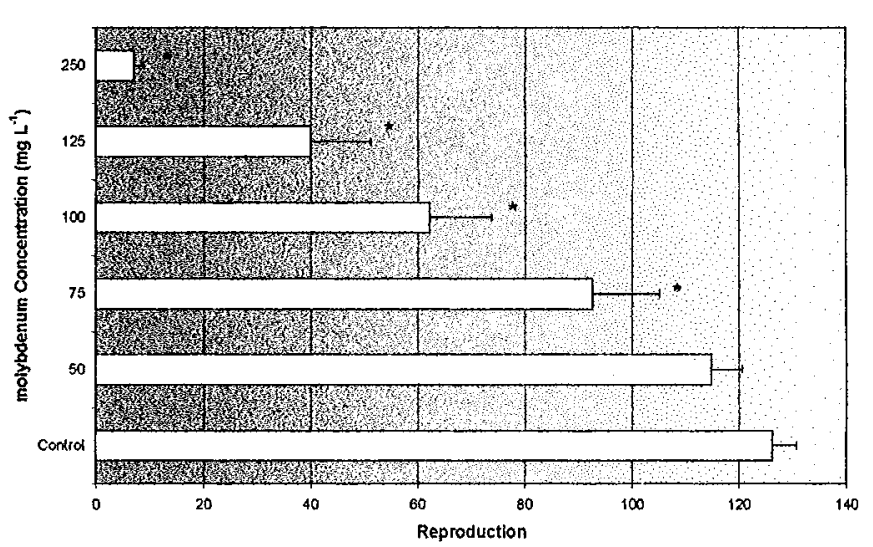

(b)

FIG. 6. Total growth (a) and total reproduction (b) for each concentration of molybdenum and for the control. Data are expressed as the mean \pm SEM. (* significantly different at $P \leq 0.05)$.

in vitro tests with colored compounds, which can lead to an over- or underestimation of the effects on enzyme activity.

\section{CONCLUSION}

Molybdenum and chromium compounds are included in the same list (List II) of European dangerous substances. The results of this study indicate great differences in toxicity between sodium dichromate and sodium molybdate to $D$. magna evaluated in acute, chronic, and acetylcholinesterase inhibition tests, with sodium molybdate being less toxic than sodium dichromate. Thus sodium molybdate seems to be preferable to sodium dichromate, at least for some industrial applications, since it is less toxic and demonstrates relatively good anticorrosive performance. Meanwhile, more studies are being done to complete the evaluation of toxicity of molybdenum compounds to several organisms.

\section{ACKNOWLEDGMENT}

This work was partially supported by Fundaçáo para a Ciência e Tecnologia (PRAXIS XXI-BD/2872/94).

\section{REFERENCES}

Adema, D. M. (1978). Daphnia magna as a test animal in acute and chronic toxicity tests. Hydrobiologia 59, 125-134.

Almeida, E., Digmantino, T. C., Figueiredo, M. O., and Sá, C. (1998). Oxidising alternative species to chromium VI in zinc galvanised steel surface treatment. Part 1-A, Morphological and chemical study. Surface Coatings Technol. 106, 8-17.

Anger, G., Halstenberg, J., Hochgeschwender, K., Uecker, G., Korallus, U., Knopf, H., Schmidt, P., and Ohlinger, M. (1986). Chromium compounds In Ullmann's Encyclopedia of Industrial Chemistry (F. Thomas Campbell, R. Pfefferkorn, and J. F. Rounsaville, Eds.), Vol. A7, pp. 67-97. Editorial Advisory Board, Weisheim.
ASTM (1980). Standard Practice for Conducting Acute Toxicity Tests with Fishes, Macroinvertebrates and Amphibians. Report E-790-80. American for the Testing and Materials, Philadelphia.

Baird, D. J., Barber, I., Bradley, M., Calow, P., and Soares, A. M. V. M. (1989). The Daphnia bioassay: A critique. Hydrobiologia 488/489, 403-406.

Baird, D. J., Barber, I., Bradley, M., Soares, A. M. V. M., and Calow, P. (1991). A comparative study of genotype sensitivity to acute toxic stress using clones of Daphnia magna Straus. Ecotoxicol. Environ. Saf. 21, 257-265.

Biestek, T., and Weber, J. (1976). Electrolytic and Chemical Conversion Coatings, pp. 1-124. Portcullis Press, Redhill, Warszawa. (Translation edited by C. R. Drapee, A. I. M., F. C. S.).

Blaise, C., Weels, P. G., and Lee, K. (1997). Microscale testing in aquatic toxicology: Introduction, historial perspective and context. In Microscale Testing in Aquatic Toxicology: Advances, Techniques, and Practice (P. G. Wells, K. Lee, and C. Blaise, Eds.), pp. 1-9. CRC Press, Boca Raton, FL.

Bradford, M. (1976). A rapid and sensitive method for the quantification of microgram quantities of protein utilising the principle of protein-dye binding. Annals Biochem. 72, 248-254.

CEC - Council of the European Communities (1976). Directive of 4 May 1976 on Pollution Caused by Certain Dangerous Substances Discharged into the Aquatic Environment of the Community (76/464/EEC, OJL 129, 18 May).

Cohen, M. D., Kargacin, B., Klein, C. B., and Costa, M. (1993). Mechanisms of chromium carcinogenicity and toxicity. Crit. Rev. Toxicol. 23(3), 255-281.

Ellman, G. L., Courtney, D., Andres, V. Jr., and Featherstone, R. M. (1961). A new and rapid colorimetric determination of acetylcholinesterase activity. Biochem. Pharmacol. 7, 88-95.

EPA (1989). Short-Term Methods for Estimating the Chronic Toxicity of Effluents and Receiving Waters to Freshwater Organisms. Environmental Protection Agency. EPA/600/4/001.

Finney, D. J. (1971). Probit Analysis, 3rd ed. Cambridge Univ. Press, Cambridge.

Guilhermino, L., Barros, P., Silva, M. C., and Soares, A. M. V. M. (1998). Should the use of inhibition of cholinesterases as a specific biomarker for organophosphate and carbamate pesticides be questioned? Biomarkers 3(2), 157-163. 
Guilhermino, L., Diamantino, T. C., Ribeiro, R., Gonçalves, F., and Soares, A. M. V. M. (1997). Suitability of test media containing EDTA for the evaluation of acute metal toxicity to Daphnia magna Straus. Ecotoxicol. Environ. Saf. 38, 292-295.

Guilhermino, L., Lopes, M. C., Carvalho, A. P., and Soares, A. M. V. M. (1996). Inhibition of acetylcholinesterase activity as effect criterion in acute tests with juvenile Daphnia magna. Chemosphere 32, 727-738.

Herbert, A., Guilhermino, L., Da Silva De Assis, H. C., and Hansen, P.-D., $(1995 / 1996)$. Acetylcholinesterase activity in aquatic organisms as pollution biomarker. Zeitschrift Angewandte Zool. 3, 1-15.

Kálmán, E. (1994). Routes to the development of low toxicity corrosion inhibitors for use in neutral solutions. In A Working Party Report on Corrosion Inhibitors, pp. 12-18. European Federation of Corrosion, Institute of Materials.

Kangarot, B. S. (1991). Toxicity of metals to a fresh water tubificid worm, Tubifex tubifex (Muller). Bull. Environ. Contam. Toxicol. 46, 906-912.

Labrot, F., Ribera, D., Saint Denis, M., and Narbonne, J. F. (1996). In vitro and in vivo studies of potential biomarkers of lead and uranium contamination: Lipid peroxidation, acetylcholinesterase, catalase, and glutathione peroxidade activities in three non-mammalian species. Biomarkers 1, 21-28.

Mance, G. (1987). Pollution Threat of Heavy Metals in Aquatic Environment. Elsevier Science, London, UK.

Meer, C. Van der, Teunissen, C., and Boog, Th F. M. (1988). Toxicity of sodium, chromate and 3,4-dichroloaniline to crustaceans. Bull. Environ. Contam. Toxicol. 40, 204-211.

Pawlisz, A. V., Kent, R. A., Schneider, U. A., and Jefferson, C. (1997). Canadian water quality guidelines for chromium. Environ. Toxicol. Water Qual. 12, 185-193.

Payne, J. F., Mathieu, A., Melvin, W., and Fancey, L. L. (1996). Acetylcholinesterase, and old biomarker with a new future? Field trials in association with two urban rivers and paper mill in Newfoundland. Mar. Pollut. Bull. 23, 225-231.
Peakall, D. B. (1994). Biomarkers: The way forward in environmental assessment. Toxicol. Environ. News 1, 55-60.

Sebenik, R. F., Burkin, A. R., Laferty, J. M., Leichtfried, G., Meyer, H., Mitchell, P. C. H., Vuksovich, M. S., Chruch, D. A., Van Riper, G. G., Gilliland, J. C., and Thielke, S. A. (1990). Molybdenum and molybdenum compounds. In Ullmann's Encyclopedia of Industrial Chemistry (B. Elvers, S. Hawkins, and G. Schhulz, Eds.), Vol. A16, pp. 655-698. Editorial Advisory Board, Weisheim.

Soares, A. M. V. M., Baird, D. J., Barber, I., Bradley, M., and Calow, P. (1991). Variation in chronic stress-tolerance among artifical clone populations of D. magna Straus. An ecophysiological study. Verh. Internat. Verein. Limnol. 24, 2326.

Soares, A. M. V. M., Baird, D. J., and Calow, P. (1992). Interclonal variation in the performance of Daphina magna Straus in chronic bioassays. Environ. Toxicol. Chem. 11, 1477-1483.

Tang, P. T., Bech-Nielsen, G., and Moller, P. (1994). Molybdate-based alternatives to chromating as a passivation treatment for zinc. Plating Surface Finishing 11, 20-23.

Taylor, G., Baird, D. J., and Soares, A. M. V. M. (1998). Surface binding of contaminants by algae: Consequence for lethal toxicity and feeding of Daphnia magna Straus. Environ. Toxicol. Chem. 17, 412-419.

The Chemicals (Hazard Information and Packaging for Supply-Amendment Regulation) (1997). SI 1997, No. 1460.

Wharton, J. A., Wilcox, G. D., and Baldwin, K. R. (1996). Non chromate conversion coating treatments for electrodeposited zinc-nickel alloys. In Proceedings of Interfinish 96 World Congress, pp. 279-291.

Whiting, E. R., Mathieu, S., and Parker, D. W. (1994). Effects of drainage from a molybdenum mine and mill on stream macroinvertebrates communities. J. Freshwater Ecol. 9(4), 299-311.

Zar, J. H. (1996). Biostatistical Analysis, 3rd ed. Prentice-Hall. 